OPEN ACCESS

Edited by:

Mart Saarma,

University of Helsinki, Finland

Reviewed by:

Giuseppe Pasqualetti,

University of Pisa, Italy

Evangeli S. Lampri,

University of loannina, Greece

*Correspondence:

Lois M. Mulligan

mulligal@queensu.ca

Specialty section:

This article was submitted to

Clinical and Translational Physiology,

a section of the journal

Frontiers in Physiology

Received: 31 August 2018

Accepted: 11 December 2018

Published: 07 January 2019

Citation:

Mulligan LM (2019) GDNF and the RET Receptor in Cancer:

New Insights and Therapeutic Potential. Front. Physiol. 9:1873.

doi: 10.3389/fphys.2018.01873

\section{GDNF and the RET Receptor in Cancer: New Insights and Therapeutic Potential}

\author{
Lois M. Mulligan*
}

Division of Cancer Biology and Genetics, Department of Pathology and Molecular Medicine, Cancer Research Institute, Queen's University, Kingston, ON, Canada

The Glial cell line-derived neurotrophic Family Ligands (GFL) are soluble neurotrophic factors that are required for development of multiple human tissues, but which are also important contributors to human cancers. GFL signaling occurs through the transmembrane RET receptor tyrosine kinase, a well-characterized oncogene. GFLindependent RET activation, through rearrangement or point mutations occurs in thyroid and lung cancers. However, GFL-mediated activation of wildtype RET is an increasingly recognized mechanism promoting tumor growth and dissemination of a much broader group of cancers. RET and GFL expression have been implicated in metastasis or invasion in diverse human cancers including breast, pancreatic, and prostate tumors, where they are linked to poorer patient prognosis. In addition to directly inducing tumor growth in these diseases, GFL-RET signaling promotes changes in the tumor microenvironment that alter the surrounding stroma and cellular composition to enhance tumor invasion and metastasis. As such, GFL RET signaling is an important target for novel therapeutic approaches to limit tumor growth and spread and improve disease outcomes.

Keywords: GDNF, RET, oncogene, tumor microenvironment, targeted therapies

\section{INTRODUCTION}

The neurotrophins are a family of soluble neurotrophic factors, originally recognized for their abilities to regulate growth, survival and differentiation of neural-derived cell types. Neurotrophins have well characterized roles as guidance, survival and differentiation factors in developing neurons in the central (CNS) and peripheral nervous systems (PNS) and may also promote survival or regrowth of mature neurons, by binding their cell-surface receptors and stimulating downstream signals in their target cells. However, with the increasing availability of tissue and cell-specific transcriptome and proteome data, it is becoming clear that neurotrophic factors and their receptors are also broadly expressed on other, non-neural cell types, where they can contribute to cell growth, differentiation and migration and tissue maturation. Importantly, the aberrant expression or activation of these signaling complexes can allow these normal growth signals to contribute to the growth or spread of cancer cells, making expression and functions of neurotrophins and their receptors important contributors to human cancer, and potentially valuable therapeutic targets. 


\section{THE GDNF FAMILY AND RET RECEPTOR}

The Glial Cell-line Derived Neurotrophic Factors (GDNF) are a family of neurotrophins with similarities to the transforming growth factor $\beta$ growth regulatory proteins. There are four structurally similar family members: GDNF, neurturin (NRTN), artemin (ARTN), and persephin (PSPN) that are recruited to corresponding non-signaling co-receptors of the GDNF Family Receptors $\alpha$ (GFR $\alpha 1-4)$, which are tethered to the plasma membrane through glycosylphosphatidylinositol-anchors (Airaksinen and Saarma, 2002; Figure 1). GDNF Family Ligands (GFL) and GFR $\alpha$ family members have distinct but overlapping tissue-specific expression patterns that determine their biological roles, however, all GFL-GFR $\alpha$ complexes signal through a single transmembrane receptor, the RET (REarranged during Transfection) tyrosine kinase (Mulligan, 2014). GFLGFR $\alpha$ complexes associate with RET's large extracellular domain, promoting dimerization and activation of its intracellular kinase domain, leading to stimulation of multiple downstream pathways (Mulligan, 2014; Figure 1). In early development, GFL-RET signals promote proliferation and migration of neural crestderived cells to populate neuroendocrine organs and contribute to the development of central and peripheral nerve lineages, most notably the enteric nervous system (Avantaggiato et al., 1994; Schuchardt et al., 1994). In the genitourinary system, activation of RET receptor signaling is essential for growth and formation of the kidney, and later for maturation of spermatogonia (Schuchardt et al., 1996; Meng et al., 2000). More recently, important roles for GFL-RET in formation of the Peyer's patches, lymphoid structures in the gut, and the maintenance and expansion of hematopoietic stem cells have been recognized (Vargas-Leal et al., 2005; Veiga-Fernandes et al., 2007; Fonseca-Pereira et al., 2014). However, the developmentally important processes of cell proliferation and migration and stem cell renewal can also be "hijacked" to promote the growth and spread of cancer. RET is a well characterized contributor to the neoplastic process, acting as an oncogenic driver in several cancers, and has been more recently recognized as a critical determinant of invasion and spread in diverse tumor types (Mulligan, 2014). These processes can be GFL-independent or dependent, with variations depending on the type of tumor and the mechanisms leading to stimulation of RET receptor signaling. Although GFL-GFR $\alpha$ complexes have been demonstrated to induce intracellular signaling through other receptors (Paratcha et al., 2003; Popsueva et al., 2003), their role in RET-associated processes is best described in the cancer setting and will be the focus here.

\section{RET DEPENDENT, GFL INDEPENDENT CANCERS}

Oncogenic mutations that constitutively activate the RET receptor in the absence of GFLs have been recognized for over 30 years (Fusco et al., 1987; Mulligan et al., 1993). Clinically, screening for these mutations can be a valuable tool in establishing differential diagnosis and guiding disease management. RET mutations fall into two distinct classes based on mutational mechanisms and are consistently associated with distinct tumor types.

\section{RET Gene Rearrangements}

Somatic rearrangements of the RET gene, resulting from chromosomal rearrangements or inversions, lead to the juxtaposition of the RET intracellular kinase domain sequences with $\mathrm{N}$-terminal sequences from another protein which contain dimerization domains such as coiled-coil motifs (Romei et al., 2016). RET fusions have been found in 10-20\% of papillary thyroid carcinoma (PTC), $\sim 1-2 \%$ of non-small-cell lung carcinoma (NSCLC), and more recently, in 3\% of Spitzoid tumors (Wiesner et al., 2014; Romei et al., 2016; Drilon et al., 2018a; Liang et al., 2018). Increasingly, deep sequencing approaches on a wider variety of tumors are identifying less frequent $R E T$ rearrangements in other cancer types including chronic myelomonocytic leukemia and colorectal, breast, ovarian and head and neck tumors (Ballerini et al., 2012; Kato et al., 2017; Gozgit et al., 2018; Mulligan, 2018; Paratala et al., 2018; Pietrantonio et al., 2018; Skalova et al., 2018).

The chimeric RET fusion proteins generated in response to these rearrangements, localize in the cytosol and are constitutively active in the absence of any GFL. Because of their location, they are able to escape many of the processes that regulate a membrane-associated RET protein and promote sustained activation of downstream survival and growth pathways (Richardson et al., 2009; Xing, 2013). Over 30 RET fusion partner genes have been identified to date, and the distribution of different partners varies amongst tumor types. For example, the kinesin family 5B-RET gene rearrangement is the most commonly found in lung adenocarcinoma but is rare in other tumor types, while coiled-coil domain containing 6-RET rearrangements are common in PTC and several tumor types (Romei et al., 2016; Gautschi et al., 2017; Ferrara et al., 2018).

Identification of RET mutations can provide valuable prognostic and predictive tools to guide patient management. In PTC, RET rearrangements appear to be an early event in tumourigenesis (Viglietto et al., 1995). Although not essential for PTC formation, presence of a RET fusion protein or increased expression is linked to more malignant phenotypes including regional invasion and lymph node metastasis (Miki et al., 1999; Wang et al., 2008; Yip et al., 2015; Khan et al., 2018). Thus, RET rearrangements are an important marker for risk of malignancy in fine needle aspirates of thyroid nodules with indeterminate cytology. As part of a positive predictive multigene panel (e.g., ThyroSec v3, or ThyGenX/ThyraMIR), recognition of RET variants can help to distinguish benign lesions from cancer and identify cases requiring surgery (Sapio et al., 2007; Onenerk et al., 2017; Paschke et al., 2017; Steward et al., 2018). In contrast to PTC, RET mutations appear to be oncogenic drivers in NSCLC, and are more common in younger never-smokers (Wang R. et al., 2012; Tsuta et al., 2014; Gautschi et al., 2017). Although RET rearrangements are infrequent, screening as part of a multigene panel or in patients where other lung cancer genes have been excluded, is recommended to identify 


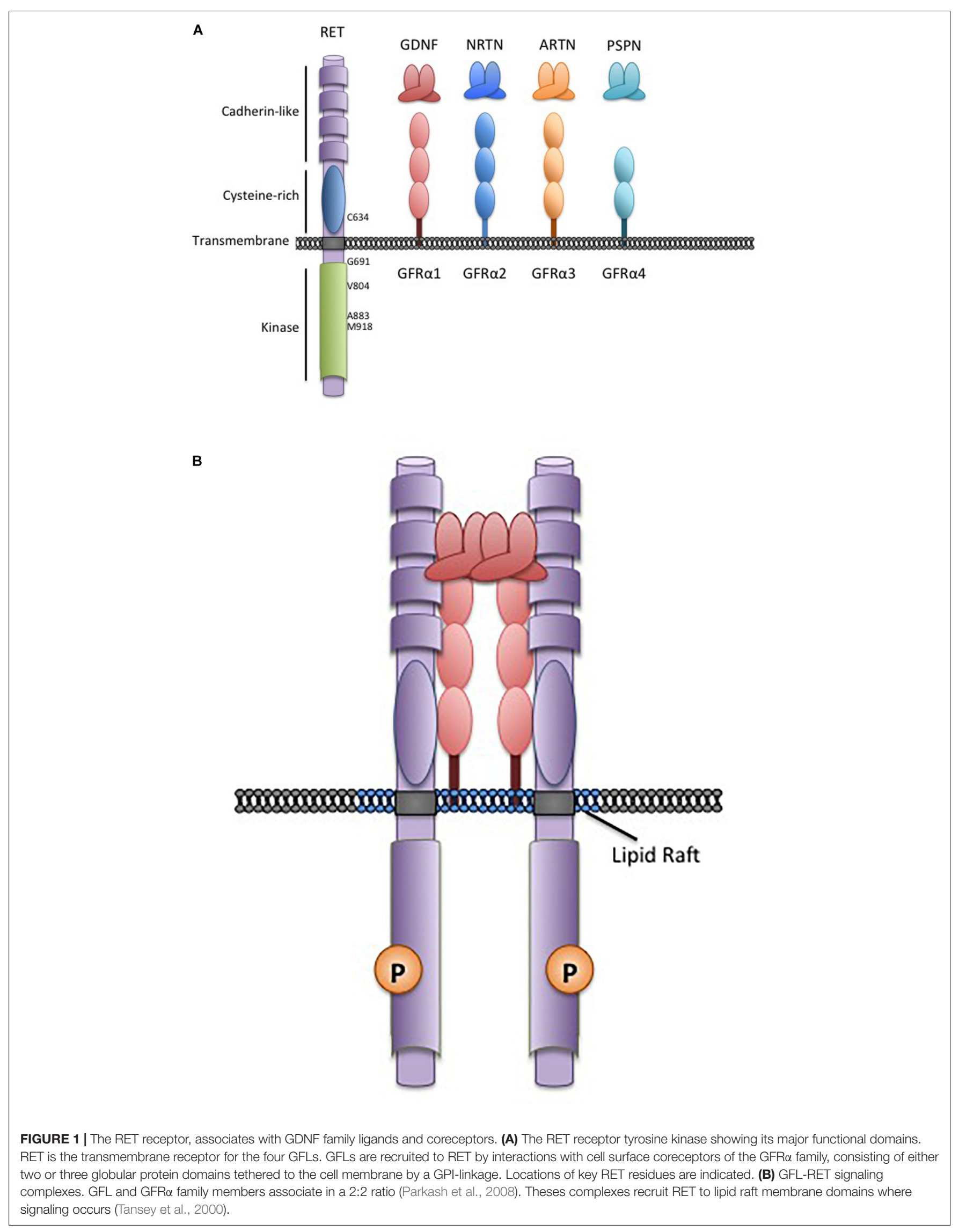


patients who may benefit from RET targeted therapies (below) (Kalemkerian et al., 2018). Interestingly, recent studies indicate that increased expression of wildtype RET occurs in an even larger pool of NSCLC, where it may be linked to poor tumor differentiation (Tan et al., 2018), suggesting that, in addition to RET fusions, GFL-RET signaling may also contribute to these tumors.

\section{RET Point Mutations}

In contrast, gain-of-function point mutations in the RET receptor give rise to multiple endocrine neoplasia 2 (MEN2), an inherited cancer syndrome characterized by medullary thyroid cancers (MTC) and the adrenal tumor pheochromocytoma (Mulligan, 2014; Wells, 2018). Similar mutations also occur somatically in 40-65\% sporadic MTC where they are an important biomarker that identifies more aggressive disease (Mulligan, 2014; Vuong et al., 2018; Wells, 2018). Interestingly, unlike RET rearrangements, activating RET point mutations are extremely rare outside of the neuroendocrine tumors. In MEN2, mutations in the RET extracellular domain result in constitutive dimerization and activation, while mutations of intracellular sequences generally affect kinase autoinhibition or ATP-binding and facilitate activation of RET monomers (Mulligan, 2014; Plaza-Menacho, 2018). As a result, full-length MEN2-RET receptors at the cell membrane are constitutively active in the absence of GFLs and stimulate unregulated signaling through pathways associated with wildtype RET activity (Asai et al., 1995; Santoro et al., 1995). However, because these active RET forms localize on the cell surface, they can also associate with GFL-GFR $\alpha$ complexes, which may further enhance their oncogenic activity (Bongarzone et al., 1998; Cranston et al., 2006; Gujral et al., 2006). There are strong associations of MEN2 disease phenotype with specific RET mutations, with more severe disease associated with relatively greater increases in mutant RET kinase activity (Eng et al., 1996; Wells et al., 2015). These associations provide the basis of clinical management guidelines for patients with MEN 2. Genetic screening for RET mutations as early as possible is now the standard of care for all at-risk individuals, allowing recommendations to be tailored to the risks associated with specific RET mutations (Wells et al., 2015). For example, a specific methionine to threonine change at codon 918 (M918T) in the RET kinase domain (Figure 1), leads to a 10-fold increase in ATP-binding and RET kinase activity and is associated with the earliest disease onset and poorest prognosis (Gujral et al., 2006; Wells et al., 2015). In these cases, thyroidectomy is recommended in the first year of life, to minimize risks of MTC micrometastasis (Sanso et al., 2002; Zenaty et al., 2009; Wells et al., 2015). In patients with other "high risk" RET mutations (e.g., C634R, A883F) surgery may be delayed within the first 5 years, while a combination of biochemical monitoring and delayed surgery may be appropriate for families with other more moderate mutations and later familial disease onset (Wells et al., 2015; Voss et al., 2017). The effects of RET mutations in familial and sporadic cancers and further details of specific genotype-phenotype correlations have been well documented in recent reviews (Romei et al., 2016; Drilon et al., 2018a; Mulligan, 2018).

\section{GFL-MEDIATED RET ACTIVITY IN CANCER}

In addition to oncogenic mutations, increased expression or activity of wildtype RET is now being recognized in many additional tumor types where it may have a range of different implications. In response to GFLs, which are released at some level by many tumors as well as by many cell types in the tumor microenvironment, RET signaling can enhance growth, promote tumor spread or even affect response to therapies.

\section{Breast Cancer}

RET and GFR $\alpha 1$ are expressed in approximately $30-70 \%$ of human breast cancers (Esseghir et al., 2007; Boulay et al., 2008; Morandi et al., 2011). Recent data have suggested that RET variants or amplification may also occur in $\sim 1 \%$ of breast tumors or metastases (Paratala et al., 2018), while tumor-specific expression of GDNF and ARTN is relatively frequent and can promote autocrine activation of RET downstream signaling (Kang et al., 2009; Kan et al., 2010; Morandi et al., 2013; Nik-Zainal et al., 2016). RET expression is more common in estrogen receptor positive $(\mathrm{ER}+\mathrm{ve})$ tumors, which are the most common breast cancer subtype, but it is also detected in other subtypes (Morandi et al., 2011; Gattelli et al., 2013). Expression is higher in recurrent cancers compared to normal tissues and corresponding primary tumors and is correlated with larger tumor size, higher tumor stage and reduced metastasis-free and overall survival (Esseghir et al., 2007; Boulay et al., 2008; PlazaMenacho et al., 2010; Wang C. et al., 2012; Gattelli et al., 2013; Morandi et al., 2013). In in vitro cell and animal models of breast cancer, activation of RET signaling by GFLs enhances tumor cell proliferation, and survival and has been shown to promote estrogen-independent expression of a normally estrogen-ERdependent transcriptional profile (Esseghir et al., 2007; Boulay et al., 2008; Plaza-Menacho et al., 2010; Wang C. et al., 2012; Gattelli et al., 2013, 2018). Both the RET and GFRA1 genes are also positively regulated by estrogen-ER, suggesting a potential feedback loop enhancing growth in ER+ve tumors (Stine et al., 2011; Horibata et al., 2018).

Importantly, RET expression in breast cancer is also correlated with resistance to endocrine therapies via stimulation of the mTOR signaling pathway (Plaza-Menacho et al., 2010; Gattelli et al., 2013; Morandi et al., 2013). Treatments that target tumor responses to estrogen, including selective estrogen receptor modulators (e.g., tamoxifen), agents blocking estrogen biosynthesis (e.g., aromatase inhibitors), and estrogen receptor antagonists (e.g., fulvestrant) are an important adjuvant to first line surgery, chemotherapy or radiation for women with ER+ve breast cancers (Pagani et al., 2010; Liu et al., 2017). Acquired or intrinsic endocrine resistance to these therapies limits options to block tumor growth or recurrence in these patients (Liu et al., 2017). RET expression is frequently elevated in ER+ve tumors, and patients with RET + ve tumors are over represented amongst cases with acquired endocrine resistance, suggesting a functional link (Plaza-Menacho et al., 2010; Morandi et al., 2013). 
Recent data suggest that upregulation of GFL ligands in these tumors may facilitate the transition of these "predisposed" RETexpressing tumors to endocrine resistance (Horibata et al., 2018). Excitingly, several recent studies in preclinical animal models have suggested that targeting RET function could both limit tumor growth and resensitize tumors to endocrine therapies, prolonging the efficacy of these agents (Nguyen et al., 2015; Andreucci et al., 2016; Hatem et al., 2016; Gattelli et al., 2018).

\section{Pancreatic Cancer}

RET and GFR $\alpha$ s are expressed in $40-65 \%$ of pancreatic ductal adenocarcinomas (PDAC) and are an indicator of poorer prognosis and reduced overall survival (Zeng et al., 2008; He et al., 2014). Expression is more frequent in high grade and metastatic tumors and in patients with lymphatic and perineural invasion (Ito et al., 2005; Zeng et al., 2008). The pancreatic environment is rich in GDNF and ARTN, which are robustly secreted by PDACs themselves but also by intra- and extra-pancreatic nerves, and by macrophages in the perineural space (Ito et al., 2005; Zeng et al., 2008; Gil et al., 2010; Amit et al., 2017). Secretion of GFLs and soluble forms of GFR $\alpha 1$ within the nerve, stimulates movement of RET-expressing tumor cells along a chemotactic gradient of GFLs to invade the perineural space and move along nerve fibers toward the central nervous system, an invasive process which is strongly linked to poorer patient outcomes, neuropathy and tumor-related pain (Veit et al., 2004; Zeng et al., 2008; Gil et al., 2010; Cavel et al., 2012; He et al., 2014; Amit et al., 2016).

Interestingly, although activating RET mutations are very rare in PDAC, a common polymorphic glycine to serine sequence variant at codon 691 (G691S) in the RET intracellular juxtamembrane region is over represented in PDAC patients ( $\sim 20 \%$ cases) and has been linked to increased GDNF-dependent proliferation and invasion (Sawai et al., 2005), suggesting this variant may act as a risk allele to modify RET function.

\section{Prostate Cancer}

RET protein has been detected in $20-75 \%$ of high grade prostate adenocarcinomas (Gleason score $>3$ ) while GDNF is upregulated in both prostate tumors and surrounding stroma (Dawson et al., 1998; Dakhova et al., 2009; Ban et al., 2017). GDNFmediated RET activity also promotes cell proliferation, invasion and perineural spread in in vitro and preclinical animal models of prostate cancer and can be further enhanced in the presence of soluble forms of GFR $\alpha 1$ released by nerves (Gil et al., 2010; Liu et al., 2012; Ban et al., 2017). Upregulation of RET and GDNF is associated with increased expression of matrix degrading metalloproteinases that facilitate the invasion of tumor cells into the perineural space (Baspinar et al., 2017). Importantly, GDNF is robustly secreted by fibroblasts in the tumor environment upon treatment-induced DNA damage, which can promote prostate cancer cell proliferation and may act as a feedback mechanism contributing to treatment resistance (Huber et al., 2015).

\section{Colorectal Cancer}

The effects of GFL-mediated RET activation in colorectal cancer are less clear. RET expression is relatively low in colon adenocarcinoma and several studies have noted frequent methylation of the RET promoter, suggesting reduced RET expression may be associated with worse prognosis in some cases (Luo et al., 2013; Draht et al., 2014). Interestingly, ARTN, NRTN, GFR $\alpha 1$, and GFR $\alpha 3$ are found in colon tumors, potentially arising from gut nerves or associated with chronic inflammation of the intestine (Qiao et al., 2009; Luo et al., 2013; Han et al., 2015), which increases cancer risk, suggesting a subset of RET-expressing colon tumors may be responsive to GFL stimulation (Mendes Oliveira et al., 2018). Increasingly, whole genome profiling or focused mutation panels are identifying RET rearrangements in colorectal cancers similar to those in thyroid and lung (Le Rolle et al., 2015; Kloosterman et al., 2017; Mendes Oliveira et al., 2018; Pietrantonio et al., 2018). RET chimeric oncoproteins are rare $(0.2-0.5 \%$ cases $)$, but promote tumor growth and migration in animal and cell based models (Gozgit et al., 2018) and have been correlated with worse prognosis, poor treatment response and reduced overall survival in colon adenocarcinoma patients (Le Rolle et al., 2015). Together, these data suggest that at least in some cases, RET may act as an oncogenic driver in colon as well. Thus, further investigation is required to establish significance of RET and GFL activity in colorectal cancer.

\section{Myeloid Malignancies}

RET is expressed in myeloid tumors but is rare in lymphoid tumors (Gattei et al., 1997). Increased RET activity, mediated through NRTN or ARTN ligand complexes secreted by stromal cells, is detected in 60-70\% of Acute Myeloid Leukemia (AML) cases with myelomonocytic differentiation, where it may promote cell viability and proliferation through suppression of autophagy by mTORC1-mediated signals (Gattei et al., 1997, 1998; Camos et al., 2006; Rudat et al., 2018). Expression is higher in AML cases with worse prognosis ( $\mathrm{Yu}$ et al., 2015). In patients with AML associated with a $t(8 ; 16)(\mathrm{p} 11 ; \mathrm{p} 13)$ translocation, increased RET expression may be a result of altered levels of a group of miRNAs predicted to regulate its normal expression (Diaz-Beya et al., 2013). In a single study, rare RET rearrangements have been found in patients with the myeloproliferative disorder, chronic myelomonocytic leukemia (Ballerini et al., 2012).

\section{Other Cancers}

Elevated levels of GFL and RET expression, without mutation, are detected in a subset of several other cancers including: melanoma, glioma, neuroblastoma, seminoma, endometrial, and head and neck cancers and renal cell carcinomas (Wiesenhofer et al., 2000; Narita et al., 2009; Pandey et al., 2010; Flavin et al., 2012; Chuang et al., 2013; Kosari et al., 2014; Lin et al., 2016). In many of these diseases, RET appears to stimulate tumor cell migration or invasion and is correlated with reduced overall survival (Narita et al., 2009; Pandey et al., 2010; Chuang et al., 2013; Kosari et al., 2014; Lin et al., 2016; Pietrantonio et al., 2018). Intriguingly, RET and GFL expression is found even more broadly in cancer cell lines from various tissues, although in vivo correlates of this in primary tumors are not always available and significance in some cases is not yet clear (Fielder et al., 2018). Together, these data suggest that targeting RET may be therapeutically valuable 


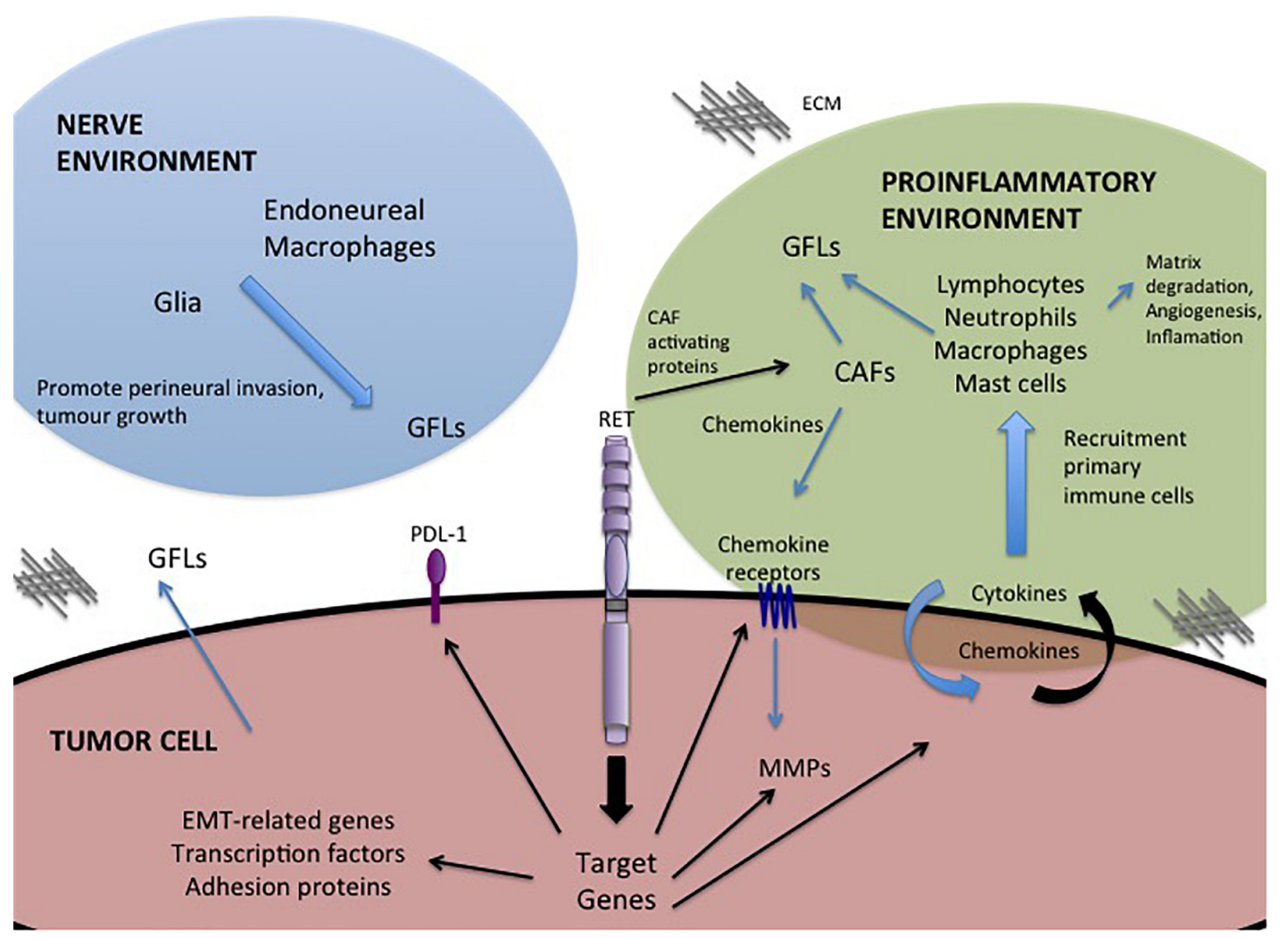

FIGURE 2 | GFL-mediated influences in the tumor microenvironment. Activation of RET receptor signaling in tumor cells promotes expression of a portfolio of proteins that regulate interactions with the tumor microenvironment. RET activity promotes changes in the composition of the tumor environment and stimulates autocrine and paracrine signals to recruit immune cells, remodel the extracellular matrix $(\mathrm{ECM})$ and promote invasion toward the neural environment. Black arrows Direct targets of RET activity.

in a broader and more diverse group of human cancers than recognized to date.

\section{GFL-RET MODULATION OF THE TUMOR MICROENVIRONMENT}

One of the most important roles of GFL-RET signaling in cancer is in modulating the relationship between the tumor and its surroundings. The tumor microenvironment is complex, comprising vessels (blood and lymph), and a plethora of cellular components including cancer-associated fibroblasts (CAF), stromal, and immune or inflammatory cells all surrounded and supported by non-cellular components of the extracellular matrix (ECM) (Figure 2). Interactions of tumor cells and their environment can result in reciprocal remodeling that enhances the ability of the tumor to grow, and invade surrounding tissues or escape immune response and initiate metastasis. In multiple cancers, stimulation of RET activity leads to changes in expression of transcription factors (e.g., SLUG, SNAIL, ZEB, TWIST), adhesion proteins (e.g., E-cadherin, $\mathrm{N}$-cadherin, vimentin) and matrix remodeling proteins (e.g., matrix metalloproteases) that can cause cancer cells to take on more mesenchymal phenotypes (Melillo et al., 2005; Lian et al., 2017; Castellone and Melillo, 2018). Cells undergoing RETmediated epithelial to mesenchymal transition (EMT) remodel their actin cytoskeleton and lose cell polarity, becoming more motile, and have enhanced abilities to degrade the ECM to promote cell invasion (Tang et al., 1998; Asai et al., 1999; Melillo et al., 2005; Lian et al., 2017).

Importantly, RET is implicated in promoting tumor-related inflammation, the infiltration of immune cells into the tumor environment, a key indicator of disease outcomes and therapeutic responses (Borrello et al., 2008). RET activation, either by oncogenic mutations or GFL stimulation, has been shown to contribute to this process by inducing expression of proinflammatory proteins including cytokines, chemokines and their receptors (Borrello et al., 2005; Puxeddu et al., 2005; Cavel et al., 2012; Menicali et al., 2012; Gattelli et al., 2013; Rusmini et al., 2014; Figure 2). When released, these molecules may act directly on the tumor cell, leading to an autocrine loop that further enhances tumor growth or motility (e.g., CXCR8/IL8), or they may promote changes in the tumor microenvironment, acting as chemoattractants for primary immune cells (lymphocytes, neutrophils, macrophages, mast cells) (Figure 2) that infiltrate the growing tumor, which in turn contribute to matrix degradation, angiogenesis and increased inflammation (Borrello et al., 2005; Cavel et al., 2012; Gattelli 
et al., 2013). For example, RET activity in thyroid, breast and pancreatic cancers can enhance tumor expression of chemokine receptor CXCR4, triggering responses to circulating chemokines released by CAFs or the tumor itself, to recruit endothelial progenitors that promote angiogenesis to sustain the growing tumor mass (Castellone et al., 2004; Borrello et al., 2005; Lu et al., 2011; Werner et al., 2017; Wang et al., 2018). Inflammatory cytokines can also promote release of GFLs by infiltrating macrophages or fibroblasts (Figure 2), particularly in the perineural environment, to further enhance RET-mediated effects (Vargas-Leal et al., 2005; Esseghir et al., 2007; Cavel et al., 2012). Several studies have shown that varying levels of RET are expressed broadly on immune cells of both myeloid and lymphoid lineages, suggesting that recruitment of these cells to the tumor microenvironment may be enhanced by higher localized GFL levels, further potentiating tumor growth and invasive spread (Borrello et al., 2005; Vargas-Leal et al., 2005; Cavel et al., 2012; Gattelli et al., 2013; Rusmini et al., 2014; Ibiza et al., 2016). Together, these data reveal a complex web of autocrine and paracrine stimulatory signals that promote remodeling of the tumor environment, facilitating the oncogenic potential of RET-expressing tumors.

\section{GFL-RET AND THE THERAPEUTIC LANDSCAPE}

As recognition of RET's impact in diverse cancers expands, it has become an increasingly important therapeutic target. As yet, there are no agents that specifically target the RET kinase in clinical use, however, multikinase inhibitors originally developed against other kinases that also inhibit RET activity are proving valuable (Drilon et al., 2018a; Redaelli et al., 2018). Specifically, two tyrosine kinase inhibitors (TKI), the VEGFR2/EGFR inhibitor vandetanib and VEGFR2/MET inhibitor cabozantinib, are approved for treatment of advanced thyroid cancer, and have been evaluated in clinical trials for RET-associated lung adenocarcinoma (Wells et al., 2012; Drilon et al., 2016, 2018a; Schlumberger et al., 2017; Yoh et al., 2017). Treatment with these TKIs has yielded significant improvements in progression free survival in MTC patients with activating RET mutations, leading to stable disease or extended response duration (Wells et al., 2012; Schlumberger et al., 2017). Notably, improved overall survival has been reported for patients with MTC harboring the RET M918T mutation, characteristic of the most aggressive form of MEN2, but is not significantly increased for patients with other RET mutations (Fox et al., 2013; Schlumberger et al., 2017). In NSCLC with RET mutations, partial responses have been reported but clinical benefit has been limited and these agents have not to date significantly improved patient outcomes (Drilon et al., 2016; Gautschi et al., 2017; Yoh et al., 2017; Ferrara et al., 2018). Similarly, in breast cancer, RET-targeting TKIs have not shown significant benefit, although previous studies have not specifically focused on RET-positive tumors (Miller et al., 2005; Bronte et al., 2017).

Further, these approved multikinase inhibitors are associated with an array of significant off-target side effects, likely due to inhibition of other kinase family members (Drilon et al., 2018a). A number of other multikinase TKIs (e.g., ponatinib, alectinib, sorafenib, lenvatinib, RXDX-105) are currently in clinical trials or early preclinical testing for RET-associated cancers (Drilon et al., 2018a; Redaelli et al., 2018). Like vandetanib and cabozantinib, these are primarily ATP-competitive inhibitors that bind conserved residues at the ATP-binding site of the kinase (Roskoski and Sadeghi-Nejad, 2018). Interestingly some of the amino acid substitution RET mutations found in MEN2 involve these "gate-keeper" residues (e.g., V804M), which determine inhibitor "fit" within the ATP-binding pocket, altering the ability of some TKIs to bind and inhibit RET (e.g., vandetanib, motesanib) (Carlomagno et al., 2004; Redaelli et al., 2018). Each of the inhibitors currently being explored has distinct abilities to inhibit RET kinase domain mutants (Liu et al., 2018). Thus, not all TKIs perform equally well at inhibiting RET mutants and patient genotype is an important determinant of optimal therapy (Carlomagno et al., 2004; Redaelli et al., 2018). Further, recent reports of acquired resistance, due to somatic mutations of this same residue, in patients treated with TKIs (Subbiah et al., 2018c), suggest that the development of novel, more selective RET inhibitors has many advantages.

A new generation of kinase inhibitors with improved selectivity for RET that also efficiently inhibit the activity of wildtype and all of the known RET mutants, are now coming to the fore. A number of promising RET-selective agents are currently in preclinical evaluation and early clinical trials (Drilon et al., 2018a; Redaelli et al., 2018). Two of the most exciting of these, BLU-667 and LOXO-292, have more than 100-fold greater selectivity for RET compared to other kinases (Subbiah et al., 2018 b,c) and are currently being evaluated in clinical trials for RET-associated lung, thyroid, colon and other solid tumors ${ }^{1}$. Early reports suggest these agents are better tolerated, with fewer off-target effects than multikinase inhibitors (Drilon et al., 2018c; Subbiah et al., 2018b,c). Preliminary results of a Phase I trial of LOXO-292, report high response rates for patients with RET fusion proteins $(\sim 69 \%)$ and also suggest some effect on brain metastases, a key challenge in managing NSCLC (Drilon et al., 2018b,c; Subbiah et al., 2018c). These studies have led to FDA designation of LOXO-292 as a breakthrough therapy for RETmutation positive thyroid carcinoma and NSCLC.

While RET-selective agents are improving targeting of RETassociated cancers now, in the future, additional approaches and combinations of therapies will further expand options. Combination therapies, coupling RET inhibitors with other therapeutic approaches may further enhance patient outcomes. Several studies, combining inhibitors of RET and mTOR signaling (e.g., everolimus) have shown increased or prolonged benefit over single agents in thyroid and breast cancer models (Plaza-Menacho et al., 2010; Gild et al., 2013; Subbiah et al., 2015). Excitingly, early reports from a clinical trial in lung cancer suggests that this combination may also improve delivery of RET inhibitor across the blood-brain barrier, essential for treating brain metastases (Plaza-Menacho et al., 2010; Gild et al., 2013; Subbiah et al., 2015, 2018a).

\footnotetext{
${ }^{1}$ clinicaltrials.gov
} 
Alternative strategies to target the GFL-RET axis are also under development. Antibody-drug conjugates targeted to RET or GFR $\alpha 1$, have demonstrated effective and specific killing of breast cancer cells in vitro and in vivo (Nguyen et al., 2015; Bhakta et al., 2017; Bosco et al., 2018). Recent studies have capitalized on adoptive T-cell immunotherapy approaches to develop GFR $\alpha 4$ targeting chimeric antigen receptor (CAR)-modified $\mathrm{T}$ cells that can promote cytotoxicity and limit growth of MTC cell lines in animal models (Bhoj et al., 2016). Interestingly, GDNF also upregulates the immune inhibitory factor Programmed Death Ligand (PDL-1) in some tumors (Lin et al., 2017; Figure 2), which when bound to its PD-1 receptor can mediate suppression of local immune responses, leading to immune evasion by tumor cells (Alsaab et al., 2017). Recent advances in cancer immunotherapy targeting the PDL-1/PD-1 immune checkpoint to release the blockade of immune responses, have shown dramatic promise as an adjuvant to established chemo or radio therapies in patients with deficiencies of DNA repair and high mutational burden (Gong et al., 2018). However, preliminary data in lung have shown low mutational burden and minimal response to immunotherapies in tumors bearing RET rearrangements, suggesting that this approach alone may not have significant benefits in this subgroup of tumors and should be coupled to other standard or targeted therapies (Sarfaty et al., 2017; Sabari et al., 2018).

\section{NON-TUMOR EFFECTS OF GFL-RET TARGETED THERAPIES}

Despite the promise of personalized therapy for RET-associated cancers, the longer term effects of RET inhibition in mature normal tissues will need to be carefully considered. GFLRET signaling is essential in development of nervous and hematopoietic systems, but also has important roles in the maintenance and survival of mature nerve lineages in the CNS and PNS. Prolonged inhibition of these signals may compromise nerve health and survival, particularly in aged neurons or in response to stress or damage (Kramer et al., 2007; Meka et al., 2015; Soba et al., 2015). Although many TKIs have limited abilities to cross the blood-brain barrier, more recent TKI and RET selective inhibitors (e.g., LOXO-292) have improved penetration into the CNS, where GFL-RET signals are important survival factors for dopaminergic neurons (Lin et al., 1993; Drinkut et al., 2016). Thus, until the long-term effects of blocking CNS GFL-signaling in the cancer setting are clear, optimal treatment of intracranial metastasis and maintaining nerve health may need to be carefully balanced.

GFL-RET signals are also important for hematopoietic stem cell maintenance and expansion in adult animals, suggesting that reduced levels as a result of treatment could impact the portfolio of immune cells generated and responses to immune challenge (Fonseca-Pereira et al., 2014). In animal models, RET ablation impairs gut homeostasis and increases the risks of inflammation or infection in the gut in response to irritants (Ibiza et al., 2016), which could also impact patient ability to remain on RET inhibitor treatment.
Finally, GFL-RET signaling has also been implicated in tumor related pain, but this relationship appears complex. GFL and RET expression are correlated with perineural invasion and resultant increased pain levels in pancreatic cancer patients (Wang et al., 2014; Amit et al., 2016). However, reports are quite variable on whether GFLs increase or decrease cancer or inflammation-related bone pain (Golden et al., 2010; Ding et al., 2017; Nencini et al., 2018). It is likely that variations in the underlying mechanisms causing pain, and potentially central versus peripheral responses, may contribute to these differences. Likewise, the effect of GFL-RET-targeted therapies on tumor pain may vary with cancer type and degree or sites of dissemination.

\section{FUTURE CONSIDERATIONS FOR GFL-RET IN CANCER}

While RET receptor mutations are well-characterized mechanisms of carcinogenesis, the much broader implications of GFL-mediated RET signaling in cancer are only beginning to be recognized. State-of-the-art diagnostic approaches, such as liquid biopsies coupled to Next Generation Sequencing, or high through-put mutational screening panels to assess circulating tumor cells or cell free tumor DNA (Hench et al., 2018; Vaughn et al., 2018), are increasing our abilities to recognize RETtargetable cancers or recurrent disease, without need for more invasive tumor biopsies (Reckamp et al., 2018).

With more intensive scrutiny of cancer genomes, RET mutations continue to be recognized, but many tumor types are now also being found to respond to GFLs released in the microenvironment by the tumor itself or neighboring cells, expanding the range of pathologies that may benefit from targeting this pathway. GFL-RET signaling both promotes inflammation in the tumor microenvironment and enhances tumor responses to it, which may provide an additional mechanism increasing proliferation and dissemination of diverse cancers. Interestingly, recent studies have also linked RET to alterations in tumor metabolism, an emerging hallmark of cancer, through a novel ligand complex involving Growth Differentiation Factor 15 (GDF15) and the GDNF Family Receptor $\alpha$-like (GFRAL) (Emmerson et al., 2017; Hsu et al., 2017; Mullican et al., 2017; Yang et al., 2017). GDF15-GFRAL-RET regulates metabolic homeostasis, particularly under stress conditions, but may also promote cancer associated anorexia or cachexia (Johnen et al., 2007; Lerner et al., 2015), suggesting that blocking RET signals may have added benefit in reducing weight loss associated with other forms of therapy. Together, these data highlight the complexity of GFL-RET signaling and the potential benefits and challenges of new therapeutic strategies for targeting this pathway that are rapidly transitioning to the clinic, to change cancer management and improve patient outcomes.

\section{AUTHOR CONTRIBUTIONS}

LM prepared the manuscript. 


\section{REFERENCES}

Airaksinen, M. S., and Saarma, M. (2002). The GDNF family: signalling, biological functions and therapeutic value. Nat. Rev. Neurosci. 3, 383-394. doi: 10.1038/ nrn812

Alsaab, H. O., Sau, S., Alzhrani, R., Tatiparti, K., Bhise, K., Kashaw, S. K., et al. (2017). PD-1 and PD-L1 checkpoint signaling inhibition for cancer immunotherapy: mechanism, combinations, and clinical outcome. Front. Pharmacol. 8:561. doi: 10.3389/fphar.2017.00561

Amit, M., Na'ara, S., and Gil, Z. (2016). Mechanisms of cancer dissemination along nerves. Nat. Rev. Cancer 16, 399-408. doi: 10.1038/nrc.2016.38

Amit, M., Na'ara, S., Leider-Trejo, L., Binenbaum, Y., Kulish, N., Fridman, E., et al. (2017). Upregulation of RET induces perineurial invasion of pancreatic adenocarcinoma. Oncogene 36, 3232-3239. doi: 10.1038/onc.2016.483

Andreucci, E., Francica, P., Fearns, A., Martin, L. A., Chiarugi, P., Isacke, C. M., et al. (2016). Targeting the receptor tyrosine kinase RET in combination with aromatase inhibitors in ER positive breast cancer xenografts. Oncotarget 7, 80543-80553. doi: 10.18632/oncotarget.11826

Asai, M., Kato, M., Asai, N., Iwashita, T., Murakami, H., Kawai, K., et al. (1999). Differential regulation of MMP-9 and TIMP-2 expression in malignant melanoma developed in metallothionein/RET transgenic mice. Jpn. J. Cancer Res. 90, 86-92. doi: 10.1111/j.1349-7006.1999.tb00670.x

Asai, N., Iwashita, T., Matsuyama, M., and Takahashi, M. (1995). Mechanism of activation of the ret proto-oncogene by multiple endocrine neoplasia $2 \mathrm{~A}$ mutations. Mol. Cell. Biol. 15, 1613-1619. doi: 10.1128/MCB.15.3.1613

Avantaggiato, V., Dathan, N. A., Grieco, M., Fabien, N., Lazzaro, D., Fusco, A., et al. (1994). Developmental expression of the RET protooncogene. Cell Growth Differ. 5, 305-311.

Ballerini, P., Struski, S., Cresson, C., Prade, N., Toujani, S., Deswarte, C., et al. (2012). RET fusion genes are associated with chronic myelomonocytic leukemia and enhance monocytic differentiation. Leukemia 26, 2384-2389. doi: 10.1038/ leu.2012.109

Ban, K., Feng, S., Shao, L., and Ittmann, M. (2017). RET signaling in prostate cancer. Clin. Cancer Res. 23, 4885-4896. doi: 10.1158/1078-0432.CCR-17-0528

Baspinar, S., Bircan, S., Ciris, M., Karahan, N., and Bozkurt, K. K. (2017). Expression of NGF, GDNF and MMP-9 in prostate carcinoma. Pathol. Res. Pract. 213, 483-489. doi: 10.1016/j.prp.2017.02.007

Bhakta, S., Crocker, L. M., Chen, Y., Hazen, M., Schutten, M. M., Li, D., et al. (2017). An anti-GDNF family receptor alpha 1 (GFRA1) antibody-drug conjugate for the treatment of hormone receptor-positive breast cancer. Mol. Cancer Ther. 17, 638-649. doi: 10.1158/1535-7163.mct-17-0813

Bhoj, V. G., Nunez-Cruz, S., Zhou, K., Arhontoulis, D., Feldman, M., Mansfield, K., et al. (2016). Abstract 2295: GDNF family receptor alpha 4 (GFRa4)-targeted adoptive T-cell immunotherapy for medullary thyroid carcinoma. Cancer Res. 76(Suppl. 14):2295. doi: 10.1158/1538-7445.am2016-2295

Bongarzone, I., Vigano, E., Alberti, L., Borrello, M. G., Pasini, B., Greco, A., et al. (1998). Full activation of MEN2B mutant RET by an additional MEN2A mutation or by ligand GDNF stimulation. Oncogene 16, 2295-2301. doi: 10. 1038/sj.onc. 1201759

Borrello, M. G., Alberti, L., Fischer, A., Degl'innocenti, D., Ferrario, C., Gariboldi, M., et al. (2005). Induction of a proinflammatory program in normal human thyrocytes by the RET/PTC1 oncogene. Proc. Natl. Acad. Sci. U.S.A. 102, 14825-14830. doi: 10.1073/pnas.0503039102

Borrello, M. G., Degl'Innocenti, D., and Pierotti, M. A. (2008). Inflammation and cancer: the oncogene-driven connection. Cancer Lett. 267, 262-270. doi: 10.1016/j.canlet.2008.03.060

Bosco, E. E., Christie, R. J., Carrasco, R., Sabol, D., Zha, J., DaCosta, K., et al. (2018). Preclinical evaluation of a GFRA1 targeted antibody-drug conjugate in breast cancer. Oncotarget 9, 22960-22975. doi: 10.18632/oncotarget. 25160

Boulay, A., Breuleux, M., Stephan, C., Fux, C., Brisken, C., Fiche, M., et al. (2008). The Ret receptor tyrosine kinase pathway functionally interacts with the ERalpha pathway in breast cancer. Cancer Res. 68, 3743-3751. doi: 10.1158/ 0008-5472.CAN-07-5100

Bronte, G., Andreis, D., Bravaccini, S., Maltoni, R., Cecconetto, L., Schirone, A., et al. (2017). Sorafenib for the treatment of breast cancer. Expert Opin. Pharmacother. 18, 621-630. doi: 10.1080/14656566.2017.1309024
Camos, M., Esteve, J., Jares, P., Colomer, D., Rozman, M., Villamor, N., et al. (2006). Gene expression profiling of acute myeloid leukemia with translocation $\mathrm{t}(8 ; 16)(\mathrm{p} 11 ; \mathrm{p} 13)$ and MYST3-CREBBP rearrangement reveals a distinctive signature with a specific pattern of HOX gene expression. Cancer Res. 66, 6947-6954. doi: 10.1158/0008-5472.CAN-05-4601

Carlomagno, F., Guida, T., Anaganti, S., Vecchio, G., Fusco, A., Ryan, A. J., et al. (2004). Disease associated mutations at valine 804 in the RET receptor tyrosine kinase confer resistance to selective kinase inhibitors. Oncogene 23, 6056-6063. doi: 10.1038/sj.onc. 1207810

Castellone, M. D., Guarino, V., De Falco, V., Carlomagno, F., Basolo, F., Faviana, P., et al. (2004). Functional expression of the CXCR4 chemokine receptor is induced by RET/PTC oncogenes and is a common event in human papillary thyroid carcinomas. Oncogene 23, 5958-5967. doi: 10.1038/sj.onc.1207790

Castellone, M. D., and Melillo, R. M. (2018). RET-mediated modulation of tumour microenvironment and immune response in MEN2. Endocr. Relat. Cancer 25, T105-T119. doi: 10.1530/ERC-17-0303

Cavel, O., Shomron, O., Shabtay, A., Vital, J., Trejo-Leider, L., Weizman, N., et al. (2012). Endoneurial macrophages induce perineural invasion of pancreatic cancer cells by secretion of GDNF and activation of RET tyrosine kinase receptor. Cancer Res. 72, 5733-5743. doi: 10.1158/0008-5472.CAN-12-0764

Chuang, J. Y., Tsai, C. F., Chang, S. W., Chiang, I. P., Huang, S. M., Lin, H. Y., et al. (2013). Glial cell line-derived neurotrophic factor induces cell migration in human oral squamous cell carcinoma. Oral Oncol. 49, 1103-1112. doi: 10. 1016/j.oraloncology.2013.08.009

Cranston, A. N., Carniti, C., Oakhill, K., Radzio-Andzelm, E., Stone, E. A., McCallion, A. S., et al. (2006). RET is constitutively activated by novel tandem mutations that alter the active site resulting in multiple endocrine neoplasia type 2B. Cancer Res. 66, 10179-10187. doi: 10.1158/0008-5472.CAN-06-0884

Dakhova, O., Ozen, M., Creighton, C. J., Li, R., Ayala, G., Rowley, D., et al. (2009). Global gene expression analysis of reactive stroma in prostate cancer. Clin. Cancer Res. 15, 3979-3989. doi: 10.1158/1078-0432.CCR-08-1899

Dawson, D. M., Lawrence, E. G., MacLennan, G. T., Amini, S. B., Kung, H. J., Robinson, D., et al. (1998). Altered expression of RET proto-oncogene product in prostatic intraepithelial neoplasia and prostate cancer. J. Natl. Cancer Inst. 90, 519-523. doi: 10.1093/jnci/90.7.519

Diaz-Beya, M., Navarro, A., Ferrer, G., Diaz, T., Gel, B., Camos, M., et al. (2013). Acute myeloid leukemia with translocation $(8 ; 16)(\mathrm{p} 11 ; \mathrm{p} 13)$ and MYST3-CREBBP rearrangement harbors a distinctive microRNA signature targeting RET proto-oncogene. Leukemia 27, 595-603. doi: 10.1038/leu.201 2.278

Ding, Z., Xu, W., Zhang, J., Zou, W., Guo, Q., Huang, C., et al. (2017). Normalizing GDNF expression in the spinal cord alleviates cutaneous hyperalgesia but not ongoing pain in a rat model of bone cancer pain. Int. J. Cancer 140, 411-422. doi: $10.1002 /$ ijc.30438

Draht, M. X., Smits, K. M., Tournier, B., Jooste, V., Chapusot, C., Carvalho, B., et al. (2014). Promoter CpG island methylation of RET predicts poor prognosis in stage II colorectal cancer patients. Mol. Oncol. 8, 679-688. doi: 10.1016/j. molonc.2014.01.011

Drilon, A., Hu, Z. I., Lai, G. G. Y., and Tan, D. S. W. (2018a). Targeting RETdriven cancers: lessons from evolving preclinical and clinical landscapes. Nat. Rev. Clin. Oncol. 15, 151-167. doi: 10.1038/nrclinonc.2017.175

Drilon, A., Lin, J. J., Filleron, T., Ni, A., Milia, J., Bergagnini, I., et al. (2018b). Brief report: frequency of brain metastases and multikinase inhibitor outcomes in patients with RET-rearranged lung cancers. J. Thorac. Oncol. 13, 1595-1601. doi: 10.1016/j.jtho.2018.07.004

Drilon, A. E., Subbiah, V., Oxnard, G. R., Bauer, T. M., Velcheti, V., Lakhani, N. J., et al. (2018c). A phase 1 study of LOXO-292, a potent and highly selective RET inhibitor, in patients with RET-altered cancers. J. Clin. Oncol. 36, 102-102. doi: 10.1200/JCO.2018.36.15_suppl.102

Drilon, A., Rekhtman, N., Arcila, M., Wang, L., Ni, A., Albano, M., et al. (2016). Cabozantinib in patients with advanced RET-rearranged non-small-cell lung cancer: an open-label, single-centre, phase 2, single-arm trial. Lancet Oncol. 17, 1653-1660. doi: 10.1016/S1470-2045(16)30562-9

Drinkut, A., Tillack, K., Meka, D. P., Schulz, J. B., Kugler, S., and Kramer, E. R. (2016). Ret is essential to mediate GDNF's neuroprotective and neuroregenerative effect in a Parkinson disease mouse model. Cell Death Dis. 7:e2359. doi: 10.1038/cddis.2016.263 
Emmerson, P. J., Wang, F., Du, Y., Liu, Q., Pickard, R. T., Gonciarz, M. D., et al. (2017). The metabolic effects of GDF15 are mediated by the orphan receptor GFRAL. Nat. Med. 23, 1215-1219. doi: 10.1038/nm.4393

Eng, C., Clayton, D., Schuffenecker, I., Lenoir, G., Cote, G., Gagel, R. F., et al. (1996). The relationship between specific RET proto-oncogene mutations and disease phenotype in multiple endocrine neoplasia type 2: international RET Mutation Consortium. JAMA 276, 1575-1579. doi: 10.1001/jama.276.19.1575

Esseghir, S., Todd, S. K., Hunt, T., Poulsom, R., Plaza-Menacho, I., Reis-Filho, J. S., et al. (2007). A role for glial cell derived neurotrophic factor induced expression by inflammatory cytokines and RET/GFR alpha 1 receptor up-regulation in breast cancer. Cancer Res. 67, 11732-11741. doi: 10.1158/0008-5472.CAN-072343

Ferrara, R., Auger, N., Auclin, E., and Besse, B. (2018). Clinical and translational implications of RET rearrangements in non-small cell lung cancer. J. Thorac. Oncol. 13, 27-45. doi: 10.1016/j.jtho.2017.10.021

Fielder, G. C., Yang, T. W., Razdan, M., Li, Y., Lu, J., Perry, J. K., et al. (2018). The GDNF family: a role in cancer? Neoplasia 20, 99-117. doi: 10.1016/j.neo.2017. 10.010

Flavin, R., Finn, S. P., Choueiri, T. K., Ingoldsby, H., Ring, M., Barrett, C., et al. (2012). RET protein expression in papillary renal cell carcinoma. Urol. Oncol. 30, 900-905. doi: 10.1016/j.urolonc.2010.08.025

Fonseca-Pereira, D., Arroz-Madeira, S., Rodrigues-Campos, M., Barbosa, I. A., Domingues, R. G., Bento, T., et al. (2014). The neurotrophic factor receptor RET drives haematopoietic stem cell survival and function. Nature 514, 98-101. doi: 10.1038/nature13498

Fox, E., Widemann, B. C., Chuk, M. K., Marcus, L., Aikin, A., Whitcomb, P. O., et al. (2013). Vandetanib in children and adolescents with multiple endocrine neoplasia type 2B associated medullary thyroid carcinoma. Clin. Cancer Res. 19, 4239-4248. doi: 10.1158/1078-0432.CCR-13-0071

Fusco, A., Grieco, M., Santoro, M., Berlingieri, M. T., Pilotti, S., Pierotti, M. A., et al. (1987). A new oncogene in human thyroid papillary carcinomas and their lymph-nodal metastases. Nature 328, 170-172. doi: 10.1038/328170a0

Gattei, V., Celetti, A., Cerrato, A., Degan, M., De Iuliis, A., Rossi, F. M., et al. (1997). Expression of the RET receptor tyrosine kinase and GDNFR-a in normal and leukemic human hematopoietic cells and stromal cells of the bone marrow microenvironment. Blood 89, 2925-2937.

Gattei, V., Degan, M., Aldinucci, D., De Iuliis, A., Rossi, F. M., Mazzocco, F. T., et al. (1998). Differential expression of the RET gene in human acute myeloid leukemia. Ann. Hematol. 77, 207-210. doi: 10.1007/s002770050444

Gattelli, A., Garcia Sola, M. E., Roloff, T. C., Cardiff, R. D., Kordon, E. C., Chodosh, L. A., et al. (2018). Chronic expression of wild-type Ret receptor in the mammary gland induces luminal tumors that are sensitive to Ret inhibition. Oncogene 37, 4046-4054. doi: 10.1038/s41388-018-0235-y

Gattelli, A., Nalvarte, I., Boulay, A., Roloff, T. C., Schreiber, M., Carragher, N., et al. (2013). Ret inhibition decreases growth and metastatic potential of estrogen receptor positive breast cancer cells. EMBO Mol. Med. 5, 1335-1350. doi: 10. 1002/emmm.201302625

Gautschi, O., Milia, J., Filleron, T., Wolf, J., Carbone, D. P., Owen, D., et al. (2017). Targeting RET in patients with RET-rearranged lung cancers: results from the global, multicenter RET registry. J. Clin. Oncol. 35, 1403-1410. doi: 10.1200/JCO.2016.70.9352

Gil, Z., Cavel, O., Kelly, K., Brader, P., Rein, A., Gao, S. P., et al. (2010). Paracrine regulation of pancreatic cancer cell invasion by peripheral nerves. J. Natl. Cancer Inst. 102, 107-118. doi: 10.1093/jnci/djp456

Gild, M. L., Landa, I., Ryder, M., Ghossein, R. A., Knauf, J. A., and Fagin, J. A. (2013). Targeting mTOR in RET mutant medullary and differentiated thyroid cancer cells. Endocr. Relat. Cancer 20, 659-667. doi: 10.1530/ERC-13-0085

Golden, J. P., Hoshi, M., Nassar, M. A., Enomoto, H., Wood, J. N., Milbrandt, J., et al. (2010). RET signaling is required for survival and normal function of nonpeptidergic nociceptors. J. Neurosci. 30, 3983-3994. doi: 10.1523/ JNEUROSCI.5930-09.2010

Gong, J., Chehrazi-Raffle, A., Reddi, S., and Salgia, R. (2018). Development of PD1 and PD-L1 inhibitors as a form of cancer immunotherapy: a comprehensive review of registration trials and future considerations. J. Immunother. Cancer 6:8. doi: 10.1186/s40425-018-0316-Z

Gozgit, J. M., Chen, T. H., Song, Y., Wardwell, S., Wang, F., Cai, J., et al. (2018). RET fusions observed in lung and colorectal cancers are sensitive to ponatinib. Oncotarget 9, 29654-29664. doi: 10.18632/oncotarget.25664
Gujral, T. S., Singh, V. K., Jia, Z., and Mulligan, L. M. (2006). Molecular mechanisms of RET receptor-mediated oncogenesis in multiple endocrine neoplasia 2B. Cancer Res. 66, 10741-10749. doi: 10.1158/0008-5472.CAN-063329

Han, T. Y., Lourenssen, S., Miller, K. G., and Blennerhassett, M. G. (2015). Intestinal smooth muscle phenotype determines enteric neuronal survival via GDNF expression. Neuroscience 290, 357-368. doi: 10.1016/j.neuroscience. 2015.01.056

Hatem, R., Labiod, D., Chateau-Joubert, S., de Plater, L., El Botty, R., Vacher, S., et al. (2016). Vandetanib as a potential new treatment for estrogen receptornegative breast cancers. Int. J. Cancer 138, 2510-2521. doi: 10.1002/ijc.29974

He, S., Chen, C. H., Chernichenko, N., He, S., Bakst, R. L., Barajas, F., et al. (2014). GFRalphal released by nerves enhances cancer cell perineural invasion through GDNF-RET signaling. Proc. Natl. Acad. Sci. U.S.A. 111, E2008-E2017. doi: 10.1073/pnas.1402944111

Hench, I. B., Hench, J., and Tolnay, M. (2018). Liquid biopsy in clinical management of breast, lung, and colorectal cancer. Front. Med. 5:9. doi: 10. 3389/fmed.2018.00009

Horibata, S., Rice, E. J., Mukai, C., Marks, B. A., Sams, K., Zheng, H., et al. (2018). ER-positive breast cancer cells are poised for RET-mediated endocrine resistance. PLoS One 13:e0194023. doi: 10.1371/journal.pone.0194023

Hsu, J. Y., Crawley, S., Chen, M., Ayupova, D. A., Lindhout, D. A., Higbee, J., et al. (2017). Non-homeostatic body weight regulation through a brainstemrestricted receptor for GDF15. Nature 550, 255-259. doi: 10.1038/nature24042

Huber, R. M., Lucas, J. M., Gomez-Sarosi, L. A., Coleman, I., Zhao, S., Coleman, R., et al. (2015). DNA damage induces GDNF secretion in the tumor microenvironment with paracrine effects promoting prostate cancer treatment resistance. Oncotarget 6, 2134-2147. doi: 10.18632/oncotarget.3040

Ibiza, S., Garcia-Cassani, B., Ribeiro, H., Carvalho, T., Almeida, L., Marques, R., et al. (2016). Glial-cell-derived neuroregulators control type 3 innate lymphoid cells and gut defence. Nature 535, 440-443. doi: 10.1038/nature18644

Ito, Y., Okada, Y., Sato, M., Sawai, H., Funahashi, H., Murase, T., et al. (2005). Expression of glial cell line-derived neurotrophic factor family members and their receptors in pancreatic cancers. Surgery 138, 788-794. doi: 10.1016/j.surg. 2005.07.007

Johnen, H., Lin, S., Kuffner, T., Brown, D. A., Tsai, V. W., Bauskin, A. R., et al. (2007). Tumor-induced anorexia and weight loss are mediated by the TGF-beta superfamily cytokine MIC-1. Nat. Med. 13, 1333-1340. doi: 10.1038/nm1677

Kalemkerian, G. P., Narula, N., Kennedy, E. B., Biermann, W. A., Donington, J., Leighl, N. B., et al. (2018). Molecular testing guideline for the selection of patients with lung cancer for treatment with targeted tyrosine kinase inhibitors: American society of clinical oncology endorsement of the college of american pathologists/international association for the study of lung cancer/association for molecular pathology clinical practice guideline update. J. Clin. Oncol. 36, 911-919. doi: 10.1200/JCO.2017.76.7293

Kan, Z., Jaiswal, B. S., Stinson, J., Janakiraman, V., Bhatt, D., Stern, H. M., et al. (2010). Diverse somatic mutation patterns and pathway alterations in human cancers. Nature 466, 869-873. doi: 10.1038/nature09208

Kang, J., Perry, J. K., Pandey, V., Fielder, G. C., Mei, B., Qian, P. X., et al. (2009). Artemin is oncogenic for human mammary carcinoma cells. Oncogene 28, 2034-2045. doi: 10.1038/onc.2009.66

Kato, S., Subbiah, V., Marchlik, E., Elkin, S. K., Carter, J. L., and Kurzrock, R. (2017). RET aberrations in diverse cancers: next-generation sequencing of 4,871 patients. Clin. Cancer Res. 23, 1988-1997. doi: 10.1158/1078-0432.CCR-161679

Khan, M. S., Qadri, Q., Makhdoomi, M. J., Wani, M. A., Malik, A. A., Niyaz, M., et al. (2018). RET/PTC gene rearrangements in thyroid carcinogenesis: assessment and clinico-pathological correlations. Pathol. Oncol. Res. doi: 10.1007/s12253-0180540-3 [Epub ahead of print].

Kloosterman, W. P., van den Braak, R. R. J. C., Pieterse, M., van Roosmalen, M. J., Sieuwerts, A. M., Stangl, C., et al. (2017). A systematic analysis of oncogenic gene fusions in primary colon cancer. Cancer Res. 77, 3814-3822. doi: 10.1158/ 0008-5472.Can-16-3563

Kosari, F., Ida, C. M., Aubry, M. C., Yang, L., Kovtun, I. V., Klein, J. L., et al. (2014). ASCL1 and RET expression defines a clinically relevant subgroup of lung adenocarcinoma characterized by neuroendocrine differentiation. Oncogene 33, 3776-3783. doi: 10.1038/onc.2013.359 
Kramer, E. R., Aron, L., Ramakers, G. M., Seitz, S., Zhuang, X., Beyer, K., et al. (2007). Absence of Ret signaling in mice causes progressive and late degeneration of the nigrostriatal system. PLoS Biol. 5:e39. doi: 10.1371/journal. pbio.0050039

Le Rolle, A. F., Klempner, S. J., Garrett, C. R., Seery, T., Sanford, E. M., Balasubramanian, S., et al. (2015). Identification and characterization of RET fusions in advanced colorectal cancer. Oncotarget 6, 28929-28937. doi: 10. 18632/oncotarget.4325

Lerner, L., Hayes, T. G., Tao, N. J., Krieger, B., Feng, B., Wu, Z. H., et al. (2015). Plasma growth differentiation factor 15 is associated with weight loss and mortality in cancer patients. J. Cachexia Sarcopenia Muscle 6, 317-324. doi: $10.1002 /$ jcsm. 12033

Lian, E. Y., Maritan, S. M., Cockburn, J. G., Kasaian, K., Crupi, M. J., Hurlbut, D., et al. (2017). Differential roles of RET isoforms in medullary and papillary thyroid carcinomas. Endocr. Relat. Cancer 24, 53-69. doi: 10.1530/ERC-160393

Liang, J., Cai, W., Feng, D., Teng, H., Mao, F., Jiang, Y., et al. (2018). Genetic landscape of papillary thyroid carcinoma in the Chinese population. J. Pathol. 244, 215-226. doi: 10.1002/path.5005

Lin, C., Lu, W., Ren, Z., Tang, Y., Zhang, C., Yang, R., et al. (2016). Elevated RET expression enhances EGFR activation and mediates EGFR inhibitor resistance in head and neck squamous cell carcinoma. Cancer Lett. 377, 1-10. doi: 10.1016/ j.canlet.2016.04.023

Lin, C. Z., Cao, W., Ren, Z. H., Tang, Y., Zhang, C. Y., Yang, R., et al. (2017). GDNF secreted by nerves enhances PD-L1 expression via JAK2-STAT1 signaling activation in HNSCC. Oncoimmunology 6:e1353860. doi: 10.1080/2162402X. 2017.1353860

Lin, L.-F. H., Doherty, D. H., Lile, J. D., Bektesh, S., and Collins, F. (1993). GDNF: a glial cell line-derived neurotrophic factor for midbrain dopaminergic neurons. Science 260, 1130-1132. doi: 10.1126/science.8493557

Liu, C. Y., Wu, C. Y., Petrossian, K., Huang, T. T., Tseng, L. M., and Chen, S. (2017). Treatment for the endocrine resistant breast cancer: current options and future perspectives. J. Steroid Biochem. Mol. Biol. 172, 166-175. doi: 10.1016/j.jsbmb. 2017.07.001

Liu, H., Li, X. Q., Xu, Q. H., Lv, S. F., Li, J. H., and Ma, Q. Y. (2012). Role of glial cell line-derived neurotrophic factor in perineural invasion of pancreatic cancer. Biochim. Biophys. Acta Rev. Cancer 1826, 112-120. doi: 10.1016/j.bbcan.2012. 03.010

Liu, X., Shen, T., Mooers, B. H. M., Hilberg, F., and Wu, J. (2018). Drug resistance profiles of mutations in the RET kinase domain. Br. J. Pharmacol. 175, 35043515. doi: 10.1111/bph.14395

Lu, C. L., Ji, Y., Ge, D., Guo, J., and Ding, J. Y. (2011). The expression of CXCR4 and its relationship with matrix metalloproteinase-9/vascular endothelial growth factor in esophageal squamous cell cancer. Dis. Esophagus 24, 283-290. doi: 10.1111/j.1442-2050.2010.01135.x

Luo, Y., Tsuchiya, K. D., Il Park, D., Fausel, R., Kanngurn, S., Welcsh, P., et al. (2013). RET is a potential tumor suppressor gene in colorectal cancer. Oncogene 32, 2037-2047. doi: 10.1038/onc.2012.225

Meka, D. P., Muller-Rischart, A. K., Nidadavolu, P., Mohammadi, B., Motori, E., Ponna, S. K., et al. (2015). Parkin cooperates with GDNF/RET signaling to prevent dopaminergic neuron degeneration. J. Clin. Invest. 125, 1873-1885. doi: 10.1172/JCI79300

Melillo, R. M., Castellone, M. D., Guarino, V., De Falco, V., Cirafici, A. M., Salvatore, G., et al. (2005). The RET/PTC-RAS-BRAF linear signaling cascade mediates the motile and mitogenic phenotype of thyroid cancer cells. J. Clin. Invest. 115, 1068-1081. doi: 10.1172/JCI22758

Mendes Oliveira, D., Grillone, K., Mignogna, C., De Falco, V., Laudanna, C., Biamonte, F., et al. (2018). Next-generation sequencing analysis of receptortype tyrosine kinase genes in surgically resected colon cancer: identification of gain-of-function mutations in the RET proto-oncogene. J. Exp. Clin. Cancer Res. 37:84. doi: 10.1186/s13046-018-0746-y

Meng, X., Lindahl, M., Hyvonen, M. E., Parvinen, M., de Rooij, D. G., Hess, M. W., et al. (2000). Regulation of cell fate decision of undifferentiated spermatogonia by GDNF. Science 287, 1489-1493. doi: 10.1126/science.287.5457.1489

Menicali, E., Moretti, S., Voce, P., Romagnoli, S., Avenia, N., and Puxeddu, E. (2012). Intracellular signal transduction and modification of the tumor microenvironment induced by RET/PTCs in papillary thyroid carcinoma. Front. Endocrinol. 3:67. doi: 10.3389/fendo.2012.00067
Miki, H., Kitaichi, M., Masuda, E., Komaki, K., Yamamoto, Y., and Monden, Y. (1999). ret/PTC expression may be associated with local invasion of thyroid papillary carcinoma. J. Surg. Oncol. 71, 76-81. doi: 10.1002/(SICI)10969098(199906)71:2<76::AID-JSO4>3.0.CO;2-0

Miller, K. D., Trigo, J. M., Wheeler, C., Barge, A., Rowbottom, J., Sledge, G., et al. (2005). A multicenter phase II trial of ZD6474, a vascular endothelial growth factor receptor- 2 and epidermal growth factor receptor tyrosine kinase inhibitor, in patients with previously treated metastatic breast cancer. Clin. Cancer Res. 11, 3369-3376. doi: 10.1158/1078-0432.CCR-04- 1923

Morandi, A., Martin, L. A., Gao, Q., Pancholi, S., Mackay, A., Robertson, D., et al. (2013). GDNF-RET signaling in ER-positive breast cancers is a key determinant of response and resistance to aromatase inhibitors. Cancer Res. 73, 3783-3795. doi: 10.1158/0008-5472.CAN-12-4265

Morandi, A., Plaza-Menacho, I., and Isacke, C. M. (2011). RET in breast cancer: functional and therapeutic implications. Trends Mol. Med. 17, 149-157. doi: 10.1016/j.molmed.2010.12.007

Mullican, S. E., Lin-Schmidt, X., Chin, C. N., Chavez, J. A., Furman, J. L., Armstrong, A. A., et al. (2017). GFRAL is the receptor for GDF15 and the ligand promotes weight loss in mice and nonhuman primates. Nat. Med. 23, 1150-1157. doi: 10.1038/nm.4392

Mulligan, L. M. (2014). RET revisited: expanding the oncogenic portfolio. Nat. Rev. Cancer 14, 173-186. doi: 10.1038/nrc3680

Mulligan, L. M. (2018). Exploiting insights on the RET receptor for personalized cancer medicine. Endocr. Relat. Cancer 25, T1-T12. doi: 10.1530/ERC-18-0141

Mulligan, L. M., Kwok, J. B. J., Healey, C. S., Elsdon, M. J., Eng, C., Gardner, E., et al. (1993). Germ-line mutations of the RET proto-oncogene in multiple endocrine neoplasia type 2A. Nature 363, 458-460. doi: 10.1038/363458a0

Narita, N., Tanemura, A., Murali, R., Scolyer, R. A., Huang, S., Arigami, T., et al. (2009). Functional RET G691S polymorphism in cutaneous malignant melanoma. Oncogene 28, 3058-3068. doi: 10.1038/onc.2009.164

Nencini, S., Ringuet, M., Kim, D. H., Greenhill, C., and Ivanusic, J. J. (2018). GDNF, neurturin, and artemin activate and sensitize bone afferent neurons and contribute to inflammatory bone pain. J. Neurosci. 38, 4899-4911. doi: 10.1523/JNEUROSCI.0421-18.2018

Nguyen, M., Miyakawa, S., Kato, J., Mori, T., Arai, T., Armanini, M., et al. (2015). Preclinical efficacy and safety assessment of an antibody-drug conjugate targeting the c-RET proto-oncogene for breast carcinoma. Clin. Cancer Res. 21, 5552-5562. doi: 10.1158/1078-0432.CCR-15-0468

Nik-Zainal, S., Davies, H., Staaf, J., Ramakrishna, M., Glodzik, D., Zou, X., et al. (2016). Landscape of somatic mutations in 560 breast cancer whole-genome sequences. Nature 534, 47-54. doi: 10.1038/nature17676

Onenerk, A. M., Pusztaszeri, M. P., Canberk, S., and Faquin, W. C. (2017). Triage of the indeterminate thyroid aspirate: what are the options for the practicing cytopathologist? Cancer Cytopathol. 125, 477-485. doi: 10.1002/cncy.21828

Pagani, O., Senkus, E., Wood, W., Colleoni, M., Cufer, T., Kyriakides, S., et al. (2010). International guidelines for management of metastatic breast cancer: can metastatic breast cancer be cured? J. Natl. Cancer Inst. 102, 456-463. doi: 10.1093/jnci/djq029

Pandey, V., Qian, P. X., Kang, J., Perry, J. K., Mitchell, M. D., Yin, Z., et al. (2010). Artemin stimulates oncogenicity and invasiveness of human endometrial carcinoma cells. Endocrinology 151, 909-920. doi: 10.1210/en.2009-0979

Paratala, B. S., Chung, J. H., Williams, C. B., Yilmazel, B., Petrosky, W., Williams, K., et al. (2018). RET rearrangements are actionable alterations in breast cancer. Nat. Commun. 9:4821. doi: 10.1038/s41467-018-07341-4

Paratcha, G., Ledda, F., and Ibanez, C. F. (2003). The neural cell adhesion molecule NCAM is an alternative signaling receptor for GDNF family ligands. Cell 113, 867-879. doi: 10.1016/S0092-8674(03)00435-5

Parkash, V., Leppanen, V. M., Virtanen, H., Jurvansuu, J. M., Bespalov, M. M., Sidorova, Y. A., et al. (2008). The structure of the glial cell line-derived neurotrophic factor-coreceptor complex: insights into RET signaling and heparin binding. J. Biol. Chem. 283, 35164-35172. doi: 10.1074/jbc.M802543200

Paschke, R., Cantara, S., Crescenzi, A., Jarzab, B., Musholt, T. J., and Sobrinho Simoes, M. (2017). European thyroid association guidelines regarding thyroid nodule molecular fine-needle aspiration cytology diagnostics. Eur. Thyroid J. 6, 115-129. doi: 10.1159/000468519

Pietrantonio, F., Di Nicolantonio, F., Schrock, A. B., Lee, J., Morano, F., Fuca, G., et al. (2018). RET fusions in a small subset of advanced colorectal cancers at risk of being neglected. Ann. Oncol. 29, 1394-1401. doi: 10.1093/annonc/mdy090 
Plaza-Menacho, I. (2018). Structure and function of RET in multiple endocrine neoplasia type 2. Endocr. Relat. Cancer 25, T79-T90. doi: 10.1530/ERC-17-0354

Plaza-Menacho, I., Morandi, A., Robertson, D., Pancholi, S., Drury, S., Dowsett, M., et al. (2010). Targeting the receptor tyrosine kinase RET sensitizes breast cancer cells to tamoxifen treatment and reveals a role for RET in endocrine resistance. Oncogene 29, 4648-4657. doi: 10.1038/onc.2010.209

Popsueva, A., Poteryaev, D., Arighi, E., Meng, X., Angers-Loustau, A., Kaplan, D., et al. (2003). GDNF promotes tubulogenesis of GFRalphal-expressing MDCK cells by Src-mediated phosphorylation of Met receptor tyrosine kinase. J. Cell Biol. 161, 119-129. doi: 10.1083/jcb.200212174

Puxeddu, E., Knauf, J. A., Sartor, M. A., Mitsutake, N., Smith, E. P., Medvedovic, M., et al. (2005). RET/PTC-induced gene expression in thyroid PCCL3 cells reveals early activation of genes involved in regulation of the immune response. Endocr. Relat. Cancer 12, 319-334. doi: 10.1677/erc.1.00947

Qiao, S., Iwashita, T., Ichihara, M., Murakumo, Y., Yamaguchi, A., Isogai, M., et al. (2009). Increased expression of glial cell line-derived neurotrophic factor and neurturin in a case of colon adenocarcinoma associated with diffuse ganglioneuromatosis. Clin. Neuropathol. 28, 105-112. doi: 10.5414/NPP28105

Reckamp, K. L., Rich, T. A., Chae, Y., Doebele, R. C., Iams, W. T., Oh, M., et al. (2018). "Analysis of cell-free DNA from 32,991 advanced cancers reveals novel co-occurring activating RET alterations and oncogenic signaling pathway aberrations," in Proceedings of the 109th Annual Meeting of the American Association for Cancer Research: AACR, Chicago, IL.

Redaelli, S., Plaza-Manacho, I., and LMologni, L. (2018). Novel targeted therapeutics for MEN 2. Endocr. Relat. Cancer 25, T53-T68. doi: 10.1530/ERC17-0297

Richardson, D. S., Gujral, T. S., Peng, S., Asa, S. L., and Mulligan, L. M. (2009). Transcript level modulates the inherent oncogenicity of RET/PTC oncoproteins. Cancer Res. 69, 4861-4869. doi: 10.1158/0008-5472.CAN-084425

Romei, C., Ciampi, R., and Elisei, R. (2016). A comprehensive overview of the role of the RET proto-oncogene in thyroid carcinoma. Nat. Rev. Endocrinol. 12, 192-202. doi: 10.1038/nrendo.2016.11

Roskoski, R. Jr., and Sadeghi-Nejad, A. (2018). Role of RET protein-tyrosine kinase inhibitors in the treatment RET-driven thyroid and lung cancers. Pharmacol. Res. 128, 1-17. doi: 10.1016/j.phrs.2017.12.021

Rudat, S., Pfaus, A., Cheng, Y. Y., Holtmann, J., Ellegast, J. M., Buhler, C., et al. (2018). RET-mediated autophagy suppression as targetable co-dependence in acute myeloid leukemia. Leukemia 32, 2189-2202. doi: 10.1038/s41375-0180102-4

Rusmini, M., Griseri, P., Matera, I., Pontarini, E., Ravazzolo, R., Mavilio, D., et al. (2014). Expression variability and function of the RET gene in adult peripheral blood mononuclear cells. J. Cell. Physiol. 229, 2027-2037. doi: 10.1002/jcp. 24660

Sabari, J. K., Offin, M. D., Wu, S. L., Ni, A., Halpenny, D., Montecalvo, J., et al. (2018). RET-rearranged lung cancers: immunophenotype and response to immunotherapy. J. Clin. Oncol. 36(Suppl. 15):9034. doi: 10.1200/JCO.2018. 36.15_suppl.9034

Sanso, G. E., Domene, H. M., Garcia, R., Pusiol, E., de, M., Roque, M., et al. (2002). Very early detection of RET proto-oncogene mutation is crucial for preventive thyroidectomy in multiple endocrine neoplasia type 2 children: presence of C-cell malignant disease in asymptomatic carriers. Cancer 94, 323-330. doi: 10.1002/cncr.10228

Santoro, M., Carlomagno, F., Romano, A., Bottaro, D. P., Dathan, N. A., Grieco, M., et al. (1995). Activation of RET as a dominant transforming gene by germline mutations of MEN2A and MEN2B. Science 267, 381-383. doi: 10.1126/science. 7824936

Sapio, M. R., Posca, D., Raggioli, A., Guerra, A., Marotta, V., Deandrea, M., et al. (2007). Detection of RET/PTC, TRK and BRAF mutations in preoperative diagnosis of thyroid nodules with indeterminate cytological findings. Clin. Endocrinol. 66, 678-683. doi: 10.1111/j.1365-2265.2007.02800.x

Sarfaty, M., Moore, A., Neiman, V., Dudnik, E., Ilouze, M., Gottfried, M., et al. (2017). RET fusion lung carcinoma: response to therapy and clinical features in a case series of 14 patients. Clin. Lung Cancer 18, e223-e232. doi: 10.1016/j.cllc.2016. 09.003

Sawai, H., Okada, Y., Kazanjian, K., Kim, J., Hasan, S., Hines, O. J., et al. (2005). The G691S RET polymorphism increases glial cell line-derived neurotrophic factor-induced pancreatic cancer cell invasion by amplifying mitogen-activated protein kinase signaling. Cancer Res. 65, 11536-11544. doi: 10.1158/0008-5472. CAN-05-2843

Schlumberger, M., Elisei, R., Muller, S., Schoffski, P., Brose, M., Shah, M., et al. (2017). Overall survival analysis of EXAM, a phase III trial of cabozantinib in patients with radiographically progressive medullary thyroid carcinoma. Ann. Oncol. 28, 2813-2819. doi: 10.1093/annonc/mdx479

Schuchardt, A., D’Agati, V., Larsson-Blomberg, L., Costantini, F., and Pachnis, V. (1994). Defects in the kidney and enteric nervous system of mice lacking the tyrosine kinase receptor Ret. Nature 367, 380-383. doi: 10.1038/367380a0

Schuchardt, A., D'Agati, V., Pachnis, V., and Costantini, F. (1996). Renal agenesis and hypodysplasia in ret- $k$ - mutant mice result from defects in ureteric bud development. Development 122, 1919-1929.

Skalova, A., Vanecek, T., Uro-Coste, E., Bishop, J. A., Weinreb, I., Thompson, L. D. R., et al. (2018). Molecular profiling of salivary gland intraductal carcinoma revealed a subset of tumors harboring NCOA4-RET and novel TRIM27-RET fusions: a report of 17 cases. Am. J. Surg. Pathol. 42, 1445-1455. doi: 10.1097/PAS.0000000000001133

Soba, P., Han, C., Zheng, Y., Perea, D., Miguel-Aliaga, I., Jan, L. Y., et al. (2015). The Ret receptor regulates sensory neuron dendrite growth and integrin mediated adhesion. eLife 4:e05491. doi: 10.7554/eLife.05491

Steward, D. L., Carty, S. E., Sippel, R. S., Yang, S. P., Sosa, J. A., Sipos, J. A., et al. (2018). Performance of a multigene genomic classifier in thyroid nodules with indeterminate cytology: a prospective blinded multicenter study. JAMA Oncol. doi: 10.1001/jamaoncol.2018.4616 [Epub ahead of print].

Stine, Z. E., McGaughey, D. M., Bessling, S. L., Li, S., and McCallion, A. S. (2011). Steroid hormone modulation of RET through two estrogen responsive enhancers in breast cancer. Hum. Mol. Genet. 20, 3746-3756. doi: 10.1093/hmg/ ddr291

Subbiah, V., Berry, J., Roxas, M., Guha-Thakurta, N., Subbiah, I. M., Ali, S. M., et al. (2015). Systemic and CNS activity of the RET inhibitor vandetanib combined with the mTOR inhibitor everolimus in KIF5B-RET re-arranged non-small cell lung cancer with brain metastases. Lung Cancer 89, 76-79. doi: 10.1016/ j.lungcan.2015.04.004

Subbiah, V., Cascone, T., Hess, K. R., Subbiah, I. M., Nelson, S., Morikawa, N., et al. (2018a). Multi-kinase RET inhibitor vandetanib combined with mTOR inhibitor everolimus in patients with RET rearranged non-small cell lung cancer. J. Clin. Oncol. 36(Suppl.):9035. doi: 10.1200/JCO.2018.36.15_suppl.9035

Subbiah, V., Gainor, J. F., Rahal, R., Brubaker, J. D., Kim, J. L., Maynard, M., et al. (2018b). Precision targeted therapy with BLU-667 for RET-driven cancers. Cancer Discov. 8, 836-849. doi: 10.1158/2159-8290.CD-18-0338

Subbiah, V., Velcheti, V., Tuch, B. B., Ebata, K., Busaidy, N. L., Cabanillas, M. E., et al. (2018c). Selective RET kinase inhibition for patients with RET-altered cancers. Ann. Oncol. 29, 1869-1876. doi: 10.1093/annonc/mdy137

Tan, L., Hu, Y. R., Tao, Y. G., Wang, B., Xiao, J., Tang, Z. J., et al. (2018). Expression and copy number gains of the RET gene in 631 early and mid stage non-small cell lung cancer cases. Thoracic Cancer 9, 445-451. doi: 10.1111/1759-7714. 12603

Tang, M. J., Worley, D., Sanicola, M., and Dressler, G. R. (1998). The RET-glial cell-derived neurotrophic factor (GDNF) pathway stimulates migration and chemoattraction of epithelial cells. J. Cell Biol. 142, 1337-1345. doi: 10.1083/ jcb.142.5.1337

Tansey, M. G., Baloh, R. H., Milbrandt, J., and Johnson, E. M. (2000). GFRalphamediated localization of RET to lipid rafts is required for effective downstream signaling, differentiation, and neuronal survival. Neuron 25, 611-623. doi: 10. 1016/S0896-6273(00)81064-8

Tsuta, K., Kohno, T., Yoshida, A., Shimada, Y., Asamura, H., Furuta, K., et al. (2014). RET-rearranged non-small-cell lung carcinoma: a clinicopathological and molecular analysis. Br. J. Cancer 110, 1571-1578. doi: 10.1038/bjc.2014.36

Vargas-Leal, V., Bruno, R., Derfuss, T., Krumbholz, M., Hohlfeld, R., and Meinl, E. (2005). Expression and function of glial cell line-derived neurotrophic factor family ligands and their receptors on human immune cells. J. Immunol. 175, 2301-2308. doi: 10.4049/jimmunol.175.4.2301

Vaughn, C. P., Costa, J. L., Feilotter, H. E., Petraroli, R., Bagai, V., Rachiglio, A. M., et al. (2018). Simultaneous detection of lung fusions using a multiplex RT-PCR next generation sequencing-based approach: a multiinstitutional research study. BMC Cancer 18:828. doi: 10.1186/s12885-0184736-4 
Veiga-Fernandes, H., Coles, M. C., Foster, K. E., Patel, A., Williams, A., Natarajan, D., et al. (2007). Tyrosine kinase receptor RET is a key regulator of Peyer's patch organogenesis. Nature 446, 547-551. doi: 10.1038/nature05597

Veit, C., Genze, F., Menke, A., Hoeffert, S., Gress, T. M., Gierschik, P., et al. (2004). Activation of phosphatidylinositol 3-kinase and extracellular signalregulated kinase is required for glial cell line-derived neurotrophic factorinduced migration and invasion of pancreatic carcinoma cells. Cancer Res. 64, 5291-5300. doi: 10.1158/0008-5472.CAN-04-1112

Viglietto, G., Chiappetta, G., Martinez-Tello, F. J., Fukunaga, F. H., Tallini, G., Rigopoulou, D., et al. (1995). RET/PTC oncogene activation is an early event in thyroid carcinogenesis. Oncogene 11, 1207-1210.

Voss, R. K., Feng, L., Lee, J. E., Perrier, N. D., Graham, P. H., Hyde, S. M., et al. (2017). Medullary thyroid carcinoma in MEN2A: ATA moderate- or high-risk RET mutations do not predict disease aggressiveness. J. Clin. Endocrinol. Metab. 102, 2807-2813. doi: 10.1210/jc.2017-00317

Vuong, H. G., Odate, T., Ngo, H. T. T., Pham, T. Q., Tran, T. T. K., Mochizuki, K., et al. (2018). Clinical significance of RET and RAS mutations in sporadic medullary thyroid carcinoma: a meta-analysis. Endocr. Relat. Cancer 25, 633641. doi: 10.1530/ERC-18-0056

Wang, C., Mayer, J. A., Mazumdar, A., and Brown, P. H. (2012). The rearranged during transfection/papillary thyroid carcinoma tyrosine kinase is an estrogendependent gene required for the growth of estrogen receptor positive breast cancer cells. Breast Cancer Res. Treat. 133, 487-500. doi: 10.1007/s10549-0111775-9

Wang, R., Hu, H., Pan, Y., Li, Y., Ye, T., Li, C., et al. (2012). RET fusions define a unique molecular and clinicopathologic subtype of non-small-cell lung cancer. J. Clin. Oncol. 30, 4352-4359. doi: 10.1200/JCO.2012.44.1477

Wang, J., Wang, H., Cai, J., Du, S., Xin, B., Wei, W., et al. (2018). Artemin regulates CXCR4 expression to induce migration and invasion in pancreatic cancer cells through activation of NF-кB signaling. Exp. Cell Res. 365, 12-23. doi: 10.1016/j.yexcr.2018.02.008

Wang, K., Demir, I. E., D’Haese, J. G., Tieftrunk, E., Kujundzic, K., Schorn, S., et al. (2014). The neurotrophic factor neurturin contributes toward an aggressive cancer cell phenotype, neuropathic pain and neuronal plasticity in pancreatic cancer. Carcinogenesis 35, 103-113. doi: 10.1093/carcin/ bgt312

Wang, Y. L., Zhang, R. M., Luo, Z. W., Wu, Y., Du, X., Wang, Z. Y., et al. (2008). High frequency of level II-V lymph node involvement in RET/PTC positive papillary thyroid carcinoma. Eur. J. Surg. Oncol. 34, 77-81. doi: 10.1016/j.ejso. 2007.08.012

Wells, S. A. Jr. (2018). Advances in the management of MEN 2. Endocr. Relat. Cancer 25, T1-T13. doi: 10.1530/ERC-17-0325

Wells, S. A. Jr., Robinson, B. G., Gagel, R. F., Dralle, H., Fagin, J. A., Santoro, M., et al. (2012). Vandetanib in patients with locally advanced or metastatic medullary thyroid cancer: a randomized, double-blind phase III trial. J. Clin. Oncol. 30, 134-141. doi: 10.1200/JCO.2011.35.5040

Wells, S. A. Jr., Asa, S. L., Dralle, H., Elisei, R., Evans, D. B., Gagel, R. F., et al. (2015). Revised American Thyroid Association guidelines for the management of medullary thyroid carcinoma. Thyroid 25, 567-610. doi: 10.1089/thy.2014. 0335

Werner, T. A., Forster, C. M., Dizdar, L., Verde, P. E., Raba, K., Schott, M., et al. (2017). CXCR4/CXCR7/CXCL12 axis promotes an invasive phenotype in medullary thyroid carcinoma. Br. J. Cancer 117, 1837-1845. doi: 10.1038/bjc. 2017.364

Wiesenhofer, B., Stockhammer, G., Kostron, H., Maier, H., Hinterhuber, H., and Humpel, C. (2000). Glial cell line-derived neurotrophic factor (GDNF) and its receptor (GFR-alpha 1) are strongly expressed in human gliomas. Acta Neuropathol. 99, 131-137. doi: 10.1007/PL00007416

Wiesner, T., He, J., Yelensky, R., Esteve-Puig, R., Botton, T., Yeh, I., et al. (2014). Kinase fusions are frequent in Spitz tumours and spitzoid melanomas. Nat. Commun. 5:3116. doi: 10.1038/ncomms4116

Xing, M. (2013). Molecular pathogenesis and mechanisms of thyroid cancer. Nat. Rev. Cancer 13, 184-199. doi: 10.1038/nrc3431

Yang, L., Chang, C. C., Sun, Z., Madsen, D., Zhu, H., Padkjaer, S. B., et al. (2017). GFRAL is the receptor for GDF15 and is required for the anti-obesity effects of the ligand. Nat. Med. 23, 1158-1166. doi: 10.1038/nm.4394

Yip, L., Nikiforova, M. N., Yoo, J. Y., McCoy, K. L., Stang, M. T., Armstrong, M. J., et al. (2015). Tumor genotype determines phenotype and disease-related outcomes in thyroid cancer: a study of 1510 patients. Ann. Surg. 262, 519-525; discussion 524-515. doi: 10.1097/SLA.0000000000001420

Yoh, K., Seto, T., Satouchi, M., Nishio, M., Yamamoto, N., Murakami, H., et al. (2017). Vandetanib in patients with previously treated RET-rearranged advanced non-small-cell lung cancer (LURET): an open-label, multicentre phase 2 trial. Lancet Respir. Med. 5, 42-50. doi: 10.1016/S2213-2600(16)30322-8 Yu, M., Wang, J., Ma, D., Chen, S., Lin, X., Fang, Q., et al. (2015). HO-1, RET and PML as possible markers for risk stratification of acute myelocytic leukemia and prognostic evaluation. Oncol. Lett. 10, 3137-3144. doi: 10.3892/ol.2015.3644

Zenaty, D., Aigrain, Y., Peuchmaur, M., Philippe-Chomette, P., Baumann, C., Cornelis, F., et al. (2009). Medullary thyroid carcinoma identified within the first year of life in children with hereditary multiple endocrine neoplasia type 2A (codon 634) and 2B. Eur. J. Endocrinol. 160, 807-813. doi: 10.1530/EJE-08-0854

Zeng, Q., Cheng, Y., Zhu, Q., Yu, Z., Wu, X., Huang, K., et al. (2008). The relationship between overexpression of glial cell-derived neurotrophic factor and its RET receptor with progression and prognosis of human pancreatic cancer. J. Int. Med. Res. 36, 656-664. doi: 10.1177/147323000803600406

Conflict of Interest Statement: The author declares that the research was conducted in the absence of any commercial or financial relationships that could be construed as a potential conflict of interest.

Copyright (c) 2019 Mulligan. This is an open-access article distributed under the terms of the Creative Commons Attribution License (CC BY). The use, distribution or reproduction in other forums is permitted, provided the original author(s) and the copyright owner(s) are credited and that the original publication in this journal is cited, in accordance with accepted academic practice. No use, distribution or reproduction is permitted which does not comply with these terms. 